GRISA, C.; ZIMMERMANN, S. A. Estado e Sociedade Civil na Promoção da Segurança Alimentar e Nutricional no Brasil: a Construção do Programa de Aquisição de Alimentos da Agricultura Familiar (PAA). Agroalimentaria, v. 21, n. 41, p. $17-36,2015$.

KAGEYAMA, A. A.; BERGAMASCO, S. M. P. P.; OLIVEIRA, J. T. A. DE. Uma tipologia dos estabelecimentos agropecuários do Brasil a partir do censo de 2006. Revista de Economia e Sociologia Rural, v. 51, n. 1, p. 105-122, 2013.

MALUF, R. S. et al. Nutrition-sensitive agriculture and the promotion of food and nutrition sovereignty and security in Brazil. Ciência \& Saúde Coletiva, v. 20, n. 8, p. 2303-2312, 2015.

MATHEUS, D. Análise da relação da política dos territórios da cidadania e a ação do capital no campo: o caso do território da cidadania do Sudoeste Paulista. [s.1.] Unesp, 2016.

PAULA, M. M. DE; KAMIMURA, Q. P.; SILVA, J. L. G. DA. Mercados institucionais na agricultura familiar: dificuldades e desafios. Revista de Política Agrícola, v. 23, n. 1, p. 33-43, 2014.

PROCÓPIO, F. DE C.; OLIVEIRA, J. T. A. DE; BORSATTO, R. S. As dificuldades para a participação de assentamentos rurais no Programa Nacional de Alimentação Escolar (PNAE): o caso de Itapeva/ SP. Retratos de Assentamentos Rurais, v. 18, n. 1, p. 361-382, 2015.

ROCHA, C. Developments in national policies for food and nutrition security in Brazil. Development Policy Review, v. 27, n. 1, p. 51-66, 2009.

SOUZA-ESQUERDO, V. F. DE; BERGAMASCO, S. M. P. P. Análise sobre o acesso aos programas de políticas públicas da agricultura familiar nos municípios do circuito das frutas (SP). Revista de Economia e Sociologia Rural, v. 52, n. 1, p. 205-222, 2014.

TRICHES, R. M.; SILVESTRI, F. Adequação das Chamadas Públicas para Aquisição de Produtos da Agricultura Familiar para a Alimentação Escolar. Desenvolvimento em Questão, v. 16, n. 44, p. 233-259, 2018.

\section{OS LIMITES, DESAFIOS E POTENCIALIDADES DA AGRICULTURA FAMILIAR NO PNAE EM MUNICÍPIOS ATINGIDOS PELA MINERAÇÃO}

Tayrine Parreira Brito

Viviane Guimarães Pereira ${ }^{2}$ Adriano Pereira Santos ${ }^{3}$

Resumo: O artigo é resultado de pesquisa desenvolvida nos municípios de Alvorada de Minas, Conceição do Mato Dentro e Dom Joaquim (MG), localizados na área de influência direta do Projeto de mineração Minas-Rio. Considerando que a situação da agricultura familiar tem se agravado na região com os impactos do projeto de mineração e também que o Programa Nacional de Alimentação Escolar (PNAE) com a implementação da Lei ${ }^{\circ}$ 11.947/2009 tem sido uma das possibilidades de incentivo e valorização da agricultura familiar, o objetivo deste trabalho foi compreender a execução do PNAE nos três municípios e identificar quais são os desafios, limites e potencialidades da participação da agricultura familiar no programa. Tratase de uma pesquisa interdisciplinar de abordagem qualitativa, realizada por meio de entrevistas semiestruturadas e pesquisa documental. Os resultados indicam o PNAE como uma política importante para a agricultura familiar, mas com limitações e desafios à participação dos (as) agricultores (as) atingidos (as) pelo projeto minerário Minas-Rio.

Palavras-chave: Política Pública; Alimentação Escolar; Organização Produtiva; Desenvolvimento Rural.

${ }^{1}$ Mestra em Desenvolvimento, Tecnologias e Sociedade pela Universidade Federal de Itajubá (2018).E-mail: tayrinepb@gmail.com

C iveridade Federal de Itajub́, participa do Programa de Mestrado dm Desenvolvimento, Tecnologias e Sociedade (Dtecs/Unifei).E-mail: vgpereira@yahoo.com.br

${ }^{3}$ Professor Adjunto do Instituto de Ciências Humanas e Letras (ICHL), da Universidade Federal de Alfenas (Unifal-Mg).E-mail: adriasantos81@gmail.com 
ABSTRACT: The article is a result of research developed in the municipalities of Alvorada de Minas, Conceição do Mato Dentro and Dom Joaquim (MG), located in the area of direct influence of the Minas-Rio Mining Project. Considering that the situation of family agriculture has worsened in the region with the impacts of the mining project, and also that the National School Feeding Program (PNAE) with the implementation of Law 11,947 / 2009 has been one of the possibilities of encouraging and valuing the family agriculture. The objective of this study was to understand the implementation of the PNAE in the three municipalities and to identify the challenges, limits and potential of family agriculture participation in the program. This is an interdisciplinary research with a qualitative approach, carried out through semi-structured interviews and documentary research. The results indicate the PNAE as an important policy for family agriculture, but with limitations and challenges to the participation of the farmers affected by the Minas-Rio mining project.

KEYwORDs: Public policy; School Feeding; Productive Organization; Rural Development.

\section{INTRODUÇão}

O Programa Nacional de Alimentação Escolar (PNAE) é um programa de política pública antigo que tem por objetivo garantir o fornecimento da merenda nas escolas públicas, nos níveis básico, fundamental e médio. A partir de 2009, com a publicação da Lei n ${ }^{\circ} 11.947$, o PNAE ganhou mais uma função social, que é a de ser também um canal de comercialização para a agricultura familiar e um mecanismo para ser fortalecimento.

Os (as) autores (as) Souza-Esquerdo e Bergamasco (2014), Grisa e Schneider (2014), Rodrigues et al. (2017) e Corrêa et al. (2017) indicaram a participação da agricultura familiar no PNAE como um grande avanço no reconhecimento do papel desta categoria social na produção de alimentos do país. Para os (as) autores (as) essa obrigatoriedade de participação da agricultura familiar ao PNAE trouxe benefícios tanto para os (as) agricultores (as) familiares, valorizando-os (as) e servindo como estímulo à organização produtiva, como para os (as) alunos (as) das escolas que consomem os alimentos frescos e passam a ter uma proximidade maior com a agricultura familiar local e também para o desenvolvimento local e regional.

Os municípios de Conceição do Mato Dentro, Alvorada de Minas e Dom
Joaquim, são municípios de porte pequeno, e possuem uma significativa população de agricultores (as) familiares e tradicionais (Censo Agropecuário, 2006). Desde 2008 estes municípios têm sofrido com os impactos do projeto de mineração da corporação transnacional Anglo American, o Projeto Minas-Rio.

De acordo com Pereira; Becker; Wildaghen (2013), Gustin e Santos (2013), Núcleo Travessia (2016), Belleze (2017) e Vieira (2017) esses impactos atingiram diretamente os modos de vida e produção da agricultura familiar local. Na pesquisa desenvolvida por Gustin e Santos (2013), os (as) autores (as) descreveram uma série de implicações que passaram a ocorrer no campo com a chegada do empreendimento, entre elas estão a desapropriação das famílias agricultoras de suas terras, a contaminação e assoreamento dos recursos hídricos, a seca das nascentes e o êxodo rural.

Tendo em vista a realidade da agricultura familiar dessa região, verificase a demanda por estratégias que possam minimizar os desmantelamentos sociais, econômicos e ambientais resultantes da mineração. Desta forma, a participação dos (as) agricultores (as) familiares ao PNAE aparece como um dos caminhos possíveis.

Neste contexto, este trabalho buscou compreender, como o PNAE tem sido executado na região e quais são os desafios, limites e possibilidades da participação da agricultura familiar no programa.

Ele é parte de uma dissertação de mestrado do Programa de PósGraduação Desenvolvimento, Tecnologias e Sociedade, da Universidade Federal de Itajubá (UNIFEI), que por sua vez, fez parte de um projeto guardachuva, intitulado de "Levantamento das potencialidades da agricultura familiar e agroecológica das comunidades rurais atingidas pela mineração nos municípios de Conceição do Mato Dentro, Alvorada de Minas e Dom Joaquim-MG" ${ }^{\prime 4}$, financiado pela Cáritas Brasileira Regional Minas Gerais ${ }^{5}$ e executado pelo Núcleo Travessia ${ }^{6}$ (Núcleo de Pesquisa, Extensão e Apoio

${ }^{4}$ Esta pesquisa teve como objetivo reconhecer o potencial da agricultura familiar, suas características e peculiaridades, para o fomento dos Projetos Alternativos Comunitários (PACs) coordenados pela Cáritas, através dos Fundos Solidários. Os PACs foram garantidos através do Termo de Ajustamento de Conduta firmado entre o Ministério Público Federal e o empreendedor, como forma de minimizar os impactos econômicos e sociais o Ministério Público Federal e
gerados pelo empreendimento.

${ }^{5}$ Organismo da Conferência Nacional dos Bispos do Brasil (CNBB), entidade ecumênica de promoção e atuação social que trabalha na defesa dos direitos humanos, da segurança alimentar e nutricional e do desenvolvimento sustentável solidário.

${ }^{6} \mathrm{O}$ Núcleo de Pesquisa, Extensão e apoio à Agricultura Familiar e Desenvolvimento Rural - Núcleo Travessia - é um grupo de pesquisa e suporte à agricultura familiar, criado em 2015, através de um coletivo de pessoas interessadas na temática sobre o rural e o campesinato. O Núcleo está ligado à linha de pesquisa Desenvolvimento e Sociedade, do Programa de Mestrado em Desenvolvimento, Tecnologias e Sociedade (PPG DTecS), da Universidade Federal de Itajubá (UNIFEI). Sua equipe é formada por professores, estudantes e profissionais. Mais informações disponíveis em: $<$ https://nucleotravessia.unifei.edu.br/>. 
à Agricultura Familiar e Desenvolvimento Rural) da Universidade Federal de Itajubá (UNIFEI), projeto este iniciado em 2015 e finalizado em agosto de 2016, registrado na Diretoria de Pesquisa e Inovação (DPI).

$\mathrm{O}$ artigo está divido em seis partes que se integram num todo argumentativo: 1) Introdução; 2) Metodologia; 3) Estrutura normativa do PNAE; 4) a gestão do programa nos municípios estudados; 5) Os desafios, limites e potencialidades de participação da agricultura familiar, 6) considerações finais; e 7) referências bibliográficas.

\section{Metodologia}

Trata-se de uma pesquisa de natureza qualitativa, que busca explicar a realidade manifestada pelos próprios sujeitos da situação social. A área de estudo foi delimitada a partir do projeto coordenado e executado pelo Núcleo Travessia, do levantamento dos potenciais produtivos da agricultura familiar dos municípios de Conceição do Mato Dentro, Alvorada de Minas e Dom Joaquim, em parceria com a Cáritas Brasileira - Regional Minas Gerais, em resposta às demandas da população rural atingida diretamente pela mineração.

Foi um trabalho construído de forma interdisciplinar, com diversos olhares sobre os temas e problemas levantados porque, além de ser resultado de demanda socialmente organizada, é marcada pela interdisciplinaridade, área na qual o programa de Mestrado está vinculado.

A interdisciplinaridade tornou-se possível por meio do Núcleo Travessia, onde pesquisadoras e pesquisadores de formações distintas (Gestão Ambiental; Economia; Engenharia Mecânica; Engenharia Ambiental; Engenharia Hídrica; Administração; História) têm se proposto a realizar estudos e projetos de desenvolvimento rural e agricultura familiar. De acordo com Fazenda; José; Santos (2016, p. 62) "o pesquisador caminha em direção a um saber interdisciplinar na medida em que se torna parceiro de seus colegas, também pesquisadores, e, juntos, passam a refletir, a estudar e a planejar coletivamente sobre suas pesquisas". Dessa forma considera-se que esta pesquisa possa ser classificada como interdisciplinar.

Foram realizadas entrevistas semiestruturadas com cinquenta e sete (as) agricultores (as) familiares (31 em Conceição do Mato Dentro, 12 em Alvorada de Minas e 14 em Dom Joaquim), um (a) nutricionista de cada prefeitura municipal e com um (a) técnico (a) extensionista do escritório da EMATER-MG de cada um dos municípios.

As entrevistas com as famílias agricultoras aconteceram entre os dias 22 e 26 de fevereiro de 2016 e com as famílias que fornecem alimentos para o programa foram nos dias 04, 05 e 06 de setembro de 2017. Embora algumas já haviam sido entrevistadas na primeira etapa de campo, o objetivo desta parte foi conhecer o que mudou para elas depois que começaram a participar do PNAE. Houve o acompanhamento da Cáritas em todas as entrevistas.

Com os (as) nutricionistas e técnicos (as) extensionistas as entrevistas foram realizadas nos dias 18,19 e 20 de maio de 2016 e o objetivo foi entender: 1) o funcionamento burocrático do PNAE nas escolas municipais; 2) a atuação do poder público sobre o programa; e 3) a atuação da EMATERMG sobre o programa

Foi feito também a leitura e análise das chamadas públicas municipais de 2016 para aquisição de alimentos da agricultura familiar, para verificar se estavam de acordo com as resoluções e normativas previstas pelo Fundo Nacional de Desenvolvimento da Educação (FNDE).

Nas análises ainda foram utilizadas as falas literais dos sujeitos entrevistados, selecionadas a partir do enquadramento das questões do roteiro com as temáticas abordadas, respeitando a estrutura de escrita do texto de modo que os relatos pudessem fundamentar as análises realizadas. As transcrições do registro de campo foram feitas conforme os cuidados descritos pela Whitaker (2002), de acordo com autora, o pesquisador não deve confundir a fonética com a ortografia, assim, não tentando transcrever pronúncias característica de grupos sociais, por meio de erros ortográficos. É preciso respeitar a articulação do discurso dos sujeitos (WHITAKER, 2002). Os relatos foram colocados entre aspas e em itálico para que seja diferenciado das citações bibliográficas diretas.

A estrutura normativa de gestão do PNAE

O FNDE é o órgão do Ministério da Educação (MEC) responsável pela implementação nacional do PNAE, é lá que são elaboradas as normativas de controle do programa. Os setores ligados tanto às Secretarias Estaduais e Municipais de Educação bem como às Escolas Federais são responsáveis por garantir, em conjunto com o FNDE, a execução do PNAE nas escolas, as quais cuidam do seu funcionamento. Tais setores são denominados por Entidades Executoras (EEx). Já as escolas/unidades onde acontece a execução são chamadas de Unidades Executoras (UEx) (BRASIL, 2009).

Os Conselhos de Alimentação Escolar (CAE's), formados pela sociedade civil, compõem também a estrutura gerencial do PNAE. É dentro destes conselhos que a sociedade acompanha, fiscaliza, avalia e faz apontamentos sobre o programa. O CAE existe em nível estadual e municipal e cabe a 
ele emitir relatórios anuais sobre os processos de execução do PNAE; caso não o faça, são geradas implicações para a liberação do recurso do próximo ano (BRASIL, 2009).

O recurso do FNDE repassado para a alimentação escolar deve ser destinado, obrigatoriamente, no mínimo $30 \%$ à compra de produtos da agricultura familiar. O FNDE recebe o repasse direto da União e posteriormente encaminha o recurso para as EEx, em dez parcelas anuais, ou seja, durante os meses letivos. Este recurso possui caráter suplementar, que quer dizer que o FNDE disponibiliza uma complementação financeira para as refeições nas escolas. As prefeituras, os governos estaduais e federais devem conceder uma contrapartida, arcando com o restante financeiro necessário para o fornecimento da alimentação escolar.

Vale ressaltar que no Artigo $14^{\circ}$ da Lei $11.947 / 2009$ foi previsto que a obrigação dos 30\% mínimos de alimentos advindos da agricultura familiar, diz respeito somente ao recurso suplementar que o FNDE encaminha; o montante que o governo federal, o estado e a prefeitura complementam não está dentro dessa obrigação (BRASIL, 2009). O valor do recurso é correspondente ao número de alunos e dias letivos, levando em consideração a modalidade de ensino (Quadro 1).

Quadro 1- Valores diários conforme as categorias de ensino.

\begin{tabular}{|l|l|}
\hline \multicolumn{1}{|c|}{ Categorias de Ensino } & \multicolumn{1}{c|}{ Valor/Dia } \\
\hline Creches & $\mathrm{R} \$ 1,07$ \\
\hline Pré-escola & $\mathrm{R} \$ 0,53$ \\
\hline Escolas indígenas e quilombolas & $\mathrm{R} \$ 0,64$ \\
\hline Ensino fundamental e médio & $\mathrm{R} \$ 0,36$ \\
\hline Educação de jovens e adultos & $\mathrm{R} \$ 0,32$ \\
\hline Ensino integral & $\mathrm{R} \$ 1,07$ \\
\hline $\begin{array}{l}\text { Programa de Fomento às Escolas de Ensino } \\
\text { Médio em Tempo Integral }\end{array}$ & $\mathrm{R} \$ 2,00$ \\
\hline $\begin{array}{l}\text { Alunos que frequentam o Atendimento } \\
\text { Educacional Especializado no contraturno }\end{array}$ & $\mathrm{R} \$ 0,53$ \\
\hline
\end{tabular}

Fonte: FNDE (2017).
A participação de um (a) nutricionista na elaboração dos cardápios é obrigatória, pois é com base no cardápio que será elaborada a chamada pública. Neste sentido, o papel do (a) nutricionista é estratégico, porque é ele (a) quem irá definir o que será pedido nas chamadas para os (as) agricultores (as), se ele (a) inclui alimentos que não são produzidos pela agricultura familiar local/regional, pode comprometer a participação das famílias e o próprio programa.

$\mathrm{O}$ fornecimento dos alimentos pela agricultura familiar acontece por meio de chamadas públicas. Elas devem ser divulgadas de acordo com as normativas do FNDE, nos espaços de grande circulação de pessoas, nos jornais e rádios locais e também no diário oficial. As famílias, segundo as regras, devem atender todo o processo burocrático exigido: apresentar a Declaração de Aptidão ao Pronaf - DAP; documentos pessoais que comprove a situação que a famílias se encontra dentro da lista de prioridades e o projeto de venda.

Para o processo de seleção dos agricultores existe uma lista de prioridade que deve ser seguida na seguinte ordem: 1) agricultores familiares locais (que moram no município onde esta sendo realizada a chamada pública), 2) as áreas de assentamento da reforma agrária, indígenas, quilombolas e comunidades tradicionais (sendo que, se estas estiverem em território local, terá prioridade sobre os demais agricultores locais), 3) as organizações formais de agricultores (as) como associação e cooperativa (esta possui prioridade em qualquer uma das prioridades descritas, exemplo: se um (a) agricultor (a) local quilombola participa de uma associação, este terá prioridade em cima do quilombola local que não participa) (BRASIL, 2009).

E para auxiliar o FNDE na implementação do PNAE, existem os Centros Colaboradores em Alimentação e Nutrição Escolar (CECANE's), que são centros de apoio formados por meio da parceria entre o FNDE e as instituições públicas de ensino superior. Os CECANE's promovem assessorias e formações aos atores envolvidos no programa.

A gestão municipal e estadual do PNAE em Conceição do Mato Dentro, Alvorada de Minas e Dom Joaquim

A gestão do programa pode ser centralizada ou descentralizada. Na gestão centralizada, Estados e municípios ficam responsáveis por fazer toda a gestão (abrem chamada pública, realizam as compras e os pagamentos). Na gestão descentralizada são as escolas que ficam responsáveis pela gestão, recebendo diretamente o repasse do recurso pelo FNDE. Na rede de ensino municipal, geralmente se utiliza da gestão centralizada, onde a secretaria de educação em conjunto com outros departamentos da prefeitura é responsável pela execução e pagamentos (BRASIL, 2009). 
A pesquisa identificou que a gestão das escolas municipais de Conceição do Mato Dentro, Alvorada de Minas e Dom Joaquim é centralizada nas prefeituras. Existindo a seguinte estrutura (Figura 1):

Figura 1 - Gestão municipal do PNAE em Conceição do Mato Dentro, Alvorada de Minas e Dom Joaquim.

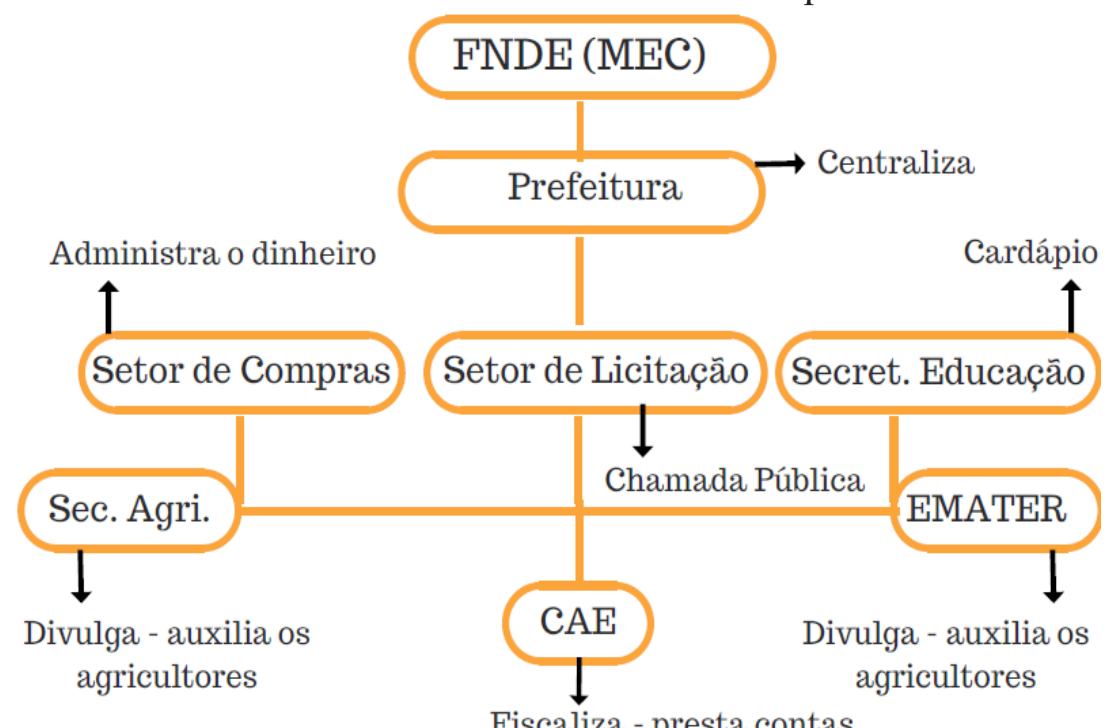

Fonte: Elaborado pelos autores.

1) O setor de compras administra o recurso [recebendo do FNDE e realizando o pagamento para os (as) agricultores (as) familiares];

2) A Secretaria de Educação encaminha a demanda dos alimentos, por meio do cardápio elaborado pelo(a) nutricionista;

3) O setor de licitação recebe a demanda e elabora a chamada pública;

4) O Conselho de Alimentação Escolar (CAE) fiscaliza e emite o parecer anual da utilização do recurso ${ }^{7}$.

5) E a divulgação das chamadas públicas é feita pela secretaria municipal de agricultura, pelo setor de comunicação da prefeitura, pela secretaria municipal de educação e pela EMATER - MG.

\footnotetext{
“'A composição do CAE deve ser a seguinte: um representante do poder executivo; dois representantes das entidades de trabalhadores da educação e discentes; dois representantes de pais de alunos; e dois representantes das entidades civis organizadas. A duração do mandato é de quatro anos e é considerado serviço público relevante não remunerado. Entre as atribuiç̃os desse Conselho, destaca-se a análise da prestação de contas do gestor, registrada no SIGPC ONLINE para a emissão do Parecer Conclusivo acerca da excuũa do Programa SIGECON O Or. SIGECON Online. O CAE é tão fundamental para a execução do Programa, que caso não seja constituído o deixarem de sanar suas pendências e não apresentarem a prestação de contas dos recursos recebidos, o FNDE poderá suspender o repasse dos recursos do PNAE!"' (FNDE, 2012)
}

A gestão das escolas estaduais acontece de forma descentralizada/ escolarizada, ou seja, diferente das escolas municipais, as escolas estaduais possuem autonomia para gerir o PNAE elas próprias com o auxílio da Superintendência Regional de Ensino, e podem abrir suas chamadas públicas e realizar os pagamentos. As prefeituras podem gerir o PNAE nas escolas estaduais caso desejem, a partir de um acordo com a Secretaria Estadual de Educação, porém, este caso não foi encontrado nos municípios estudados.

Ainda compondo a estrutura gerencial do programa, a EMATER - MG apareceu como um apoio destinado aos agricultores familiares embora seja também de sua competência colaborar na divulgação das chamadas públicas. A empresa é o único organismo dos municípios estudados que emite a Declaração de Aptidão ao Pronaf (DAP), documento importante e obrigatório para o acesso da agricultura familiar às políticas públicas.

O histórico dos percentuais na aquisição de alimentos da agricultura familiar das prefeituras municipais (Figura 2) demonstra que os municípios de Alvorada de Minas e Dom Joaquim tiveram na maior parte dos anos cumprindo com o mínimo obrigatório estabelecido em lei. Chama-se a atenção para Alvorada de Minas que chegou a adquirir os alimentos da agricultura familiar com $90 \%$ do recurso, um valor acima da média em comparação com os demais municípios brasileiros. Segundo Rocha (2016) em 2014 apenas 2.163 municípios chegaram a adquirir $30 \%$ ou mais.

Figura 2 - Percentual da compra de alimentos da agricultura familiar.

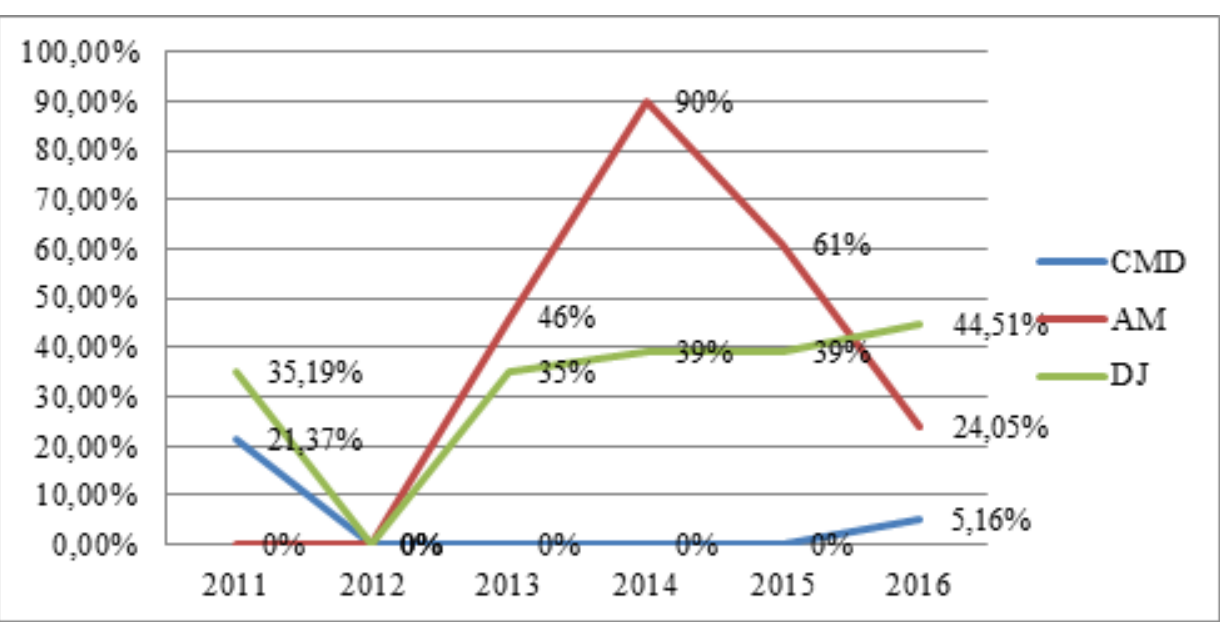

Fonte: Adaptado dos Dados da Agricultura Familiar (FNDE, 2018). 
O município de Conceição do Mato Dentro foi o único dentre os três estudados que não chegou a adquirir em nenhum ano os $30 \%$ de alimentos da agricultura familiar, chegando ao ponto de não adquirir durante quatro anos alimentos da agricultura familiar. Em termos de recurso a média anual referente ao que a prefeitura de Conceição do Mato Dentro recebeu do FNDE de 2011 a 2016 foi de R $\$ 111.468,00$, três vezes a mais do que Alvorada de Minas (R\$27.751,00) e Dom Joaquim (R\$29.498,00).

Desafios, limites e potencialidades da participação da AGRICULTURA FAMILIAR NO PNAE

Diante da realidade das famílias agricultoras atingidas pelo projeto Minas-Rio na região de estudo, verifica-se que a mineração tornou-se um empecilho para que as mesmas forneçam alimentos para merenda escolar, principalmente as famílias de Conceição do Mato Dentro, que moram nas comunidades do Passa Sete, Sapo e Água Quente, justamente as comunidades que mais sofrem com a escassez de água (BELLEZE, 2016; NÜCLEO TRAVESSIA, 2016).

Para além da mineração, a participação da agricultura familiar no PNAE, ainda encontra muitos outros desafios que podem ser superados mediante o esforço do poder público local e dos técnicos de empresas como a EMATER-MG. No entanto, esta participação enfrenta também limites, em geral de ordem estrutural que perpassam as ações do poder público local e dos agentes de desenvolvimento.

No que concerne aos desafios encontrados pela pesquisa destacamse: 1) O despreparo dos gestores públicos responsáveis; 2) As exigências burocráticas; 3) A logística; e 4) A mudança na gestão municipal. Sobre os limites vale indicar: 1) O recurso financeiro; e 2) As condições estruturais Por fim, acerca das potencialidades encontradas convém assinalar: 1) A valorização da agricultura familiar; 2) A organização produtiva; e 3) A geração de renda e emancipação social.

\section{Desafios}

Considerou-se por desafio o que é passível de mudança, o que gestores públicos e técnicos de ATER (assistência técnica e extensão rural), em apoio ao desenvolvimento rural em bases familiares e sustentáveis podem fazer para que o PNAE alcance efetivamente os seus propósitos no sentido de promover a segurança alimentar e nutricional, bem como ser um canal de comercialização para a agricultura familiar.
DESPREPARO DOS GESTORES RESPONSÁVEIS

Abreu (2014) e Silva et al. (2013) afirmaram em seus trabalhos que os gestores públicos muitas vezes não estão preparados para gerir o PNAE, desconhecendo a legislação pertinente e não tendo compreensão sobre a importância da aquisição de alimentos da agricultura familiar local. Em Conceição do Mato Dentro, Alvorada de Minas e Dom Joaquim, isso pôde ser notado no ano de 2016, quando as prefeituras dos três municípios utilizaram-se do critério de menor preço por item nas chamadas públicas. Isto é, a família que pedia o menor preço no projeto de venda ganhava a chamada, critério este considerado ilegal. De acordo com a determinação do Art. $1^{\circ}$ da Resolução 04 (FNDE, 2015), a seleção para o PNAE, deve obedecer a seguinte lista de prioridade:

$\S 1^{\circ}$ - Entre os grupos de projetos, será observada a seguinte ordem de prioridade para seleção: I - o grupo de projetos de fornecedores locais terá prioridade sobre os demais grupos. II - o grupo de projetos de fornecedores do território rural terá prioridade sobre o do estado e do País. III - o grupo de projetos do estado terá prioridade sobre o do País.

$\S 2^{\circ}$ - Em cada grupo de projetos, será observada a seguinte ordem de prioridade para seleção: I - os assentamentos de reforma agrária, as comunidades tradicionais indígenas e as comunidades quilombolas, não havendo prioridade entre estes; II - os fornecedores de gêneros alimentícios certificados como orgânicos ou agroecológicos, segundo a Lei $\mathrm{n}^{\circ} 10.831$, de 23 de dezembro de 2003; III - os Grupos Formais (organizações produtivas detentoras de Declaração de Aptidão ao PRONAF - DAP Jurídica) sobre os Grupos Informais (agricultores familiares, detentores de Declaração de Aptidão ao PRONAF - DAP Física, organizados em grupos) e estes sobre os Fornecedores Individuais (detentores de DAP Física);

O propósito do programa é pagar um preço considerado justo aos alimentos produzidos pela agricultura familiar, a fim de fortalecer e consolidar o segmento (FNDE, 2014). Para isso, os gestores devem fazer uma cotação de mercado e o valor estabelecido na chamada pública deve ser a média dessas cotações. A adoção do critério de menor preço por item provoca uma disputa entre os preços, fazendo com que os agricultores diminuam os valores dos alimentos para conseguir ganhar a chamada. No documento 
elaborado pelo FNDE de perguntas frequentes ${ }^{8}$, o item 2.9 orienta que não pode existir o critério de menor preço por item nas chamadas públicas do PNAE, devendo obedecer à lista de prioridades que já foi estabelecida.

A capacitação dos gestores que lidam com políticas públicas como o PNAE é crucial para efetividade do programa, o FNDE promove cursos e oficinas por meio dos CECANE's. Nesse sentido, desde 2016 a Cáritas, que tem atuado na região, vem oferecendo apoio na implementação do PNAE em Conceição do Mato Dentro, Alvorada de Minas e Dom Joaquim, mas ainda assim muitos gestores possuem dificuldades de entender e desvincular a chamada pública do processo de licitação. Na pesquisa feita por SouzaEsquerdo e Bergamasco (2014) sobre o Circuito das Frutas (região do Estado de São Paulo que tem a maior concentração de agricultores familiares), as autoras concluíram que o maior obstáculo na participação da agricultura familiar ao PAA e PNAE é a atuação efetiva do poder público.

Em Conceição do Mato Dentro, durante a pesquisa de campo, um agricultor afirmou que uma das maiores dificuldades que as famílias sentem é a falta de informação, e que para os agricultores o deslocamento é muito difícil e por isso, para eles ficarem sabendo, as informações devem ser levadas até eles.

Nas entrevistas realizadas com as famílias agricultoras, foi abordado sobre as informações que as mesmas tinham acerca do PNAE e consequentemente sobre suas participações. Como resultado, foram identificadas a existência de famílias que demonstraram ter total desconhecimento do PNAE, diante de falas como: "O que é isso?" (Agricultora ${ }^{3}$ de AM, 2017), bem como outras famílias que já tiveram algum tipo de contato, mas não sabiam dizer como o programa funcionava, como por exemplo, uma agricultora ${ }^{1}$ de AM (2017) que disse, "não entendemos essas coisas muito bem, fomos somente à reunião, não entregamos".

Assim, para ter uma visão geral deste desafio, foi quantificado (Tabela 1) o número de famílias que haviam participado e que conheciam o PNAE, dividindo as respostas das entrevistas nas seguintes categorias: participaram, nunca participaram, conhecem o programa e não conhecem.

As respostas obtidas das famílias de Conceição do Mato Dentro e Dom Joaquim chamaram atenção; no primeiro, $77 \%$ das famílias disseram não ter conhecimento sobre a existência do PNAE, e no segundo, $61 \%$ não conheciam. Em Alvorada de Minas todas as famílias entrevistadas disseram conhecer o PNAE e destas somente 2 ainda não haviam fornecido alimentos para merenda escolar.

8Documento disponível em: <www.fnde.gov.br/arquivos/category/116-alimentacao-escolar?download...pnaefev...>
Tabela 1 - Respostas das famílias sobre a participação no PNAE.

\begin{tabular}{|c|c|c|c|c|}
\hline & $\begin{array}{c}\text { Conceição do } \\
\text { Mato Dentro }\end{array}$ & $\begin{array}{c}\text { Alvorada de } \\
\text { Minas }\end{array}$ & Dom Joaquim & TOTAL \\
\hline Entrevistados & 31 & 11 & 13 & 55 \\
\hline Participaram & $3 \%$ & $81 \%$ & $38 \%$ & $27 \%$ \\
\hline $\begin{array}{c}\text { Nunca Participa- } \\
\text { ram }\end{array}$ & $96 \%$ & $18 \%$ & $61 \%$ & $72 \%$ \\
\hline Conhecem & $22 \%$ & $100 \%$ & $38 \%$ & $\%$ \\
\hline Não conhecem & $77 \%$ & 0 & $61 \%$ & $58 \%$ \\
\hline
\end{tabular}

Fonte: Elaborado pelos autores.

O desconhecimento por parte dos (as) agricultores (as) familiares sobre a existência do PNAE não foi algo encontrado nos trabalhos consultados sobre o tema. Na maioria das vezes os autores relacionam a baixa participação dos agricultores ao programa, com as dificuldades burocráticas e de produção (RIBEIRO; CERATTI, BROCH, 2013; SOUZA-ESQUERDO; BERGAMASCO, 2014; RODRIGUES et al, 2017).

Nesse sentido, a questão colocada é: um dos públicos alvos que era também para ser beneficiado com a implementação do PNAE sequer sabe sobre sua existência e isso pode ser algo recorrente nas demais (e diversas) regiões do país, uma vez que para as famílias agricultoras conhecerem o programa é necessário, na maioria das vezes, que os técnicos, os gestores e os extensionistas expliquem adequadamente o funcionamento e a forma como as famílias podem participar, sem este tipo de trabalho dificilmente as famílias conhecerão o PNAE, bem como qualquer outra política pública.

Em Dom Joaquim uma agricultora alegou que os atrasos no pagamento é a única dificuldade, pois ela teve um problema com uma escola estadual que ela entregou dois anos seguidos e até o momento da entrevista ela ainda não havia recebido.

São situações desafiadoras para o poder público local, que não limita a execução do programa, mas que pode torná-lo inviável para as famílias agricultoras, sendo um problema, contudo, que pode ser resolvido em âmbito local.

\section{EXIGÊNCIAS BUROCRÁTICAS}

Outro desafio para agricultura familiar participar do programa são as diversas exigências burocráticas, que fazem com que famílias sem 
acompanhamento técnico, dificilmente entendam e resolvam sozinhas os trâmites. Segundo Castro e Bombardi (2013, p. 15) entre os maiores desafios para participação das famílias agricultoras no PNAE "é a falta de documentação para regularizar o processo de compra". É necessário que exista um técnico acompanhando todo o processo de organização e elaboração dos documentos. No trabalho realizado por Camargo, Baccarin e Silva (2012, p. 12) os agricultores e gestores pesquisados apontaram a falta de ATER como um dos principais problemas, e "ambos reconhecem a importância desse serviço para capacitar os agricultores, ajudar a elaborar os projetos de venda e colocar agricultores e prefeitura em contato".

Nas entrevistas com as famílias que fornecem alimentos para o PNAE nos municípios estudados, foi ressaltada a atuação dos técnicos de Ater (EMATER e Cáritas). Para uma Agricultora de DJ³ (2017) o acompanhamento da EMATER é importante, porque cada planta tem um desenvolvimento diferente e é preciso ajuda para fazer o manejo correto. Outro Agricultor de $\mathrm{CMD}^{1}$ (2017), disse que "tem que ter auxilio, informações técnicas para ter um produto melhor".

Em Minas Gerais, de acordo com a Secretaria de Estado de Agricultura, Pecuária e Abastecimento-SEAPA/MG (2015) cabe à EMATER (empresa que faz o serviço público de Ater no estado): “a emissão da DAP, a orientação e elaboração de projetos, até mesmo a capacitação dos agricultores em boas práticas de produção". Só no ano de 2015, a EMATER conseguiu orientar 8.536 famílias para entrega de alimentos ao PNAE no estado (SEAPA, 2015).

Nos três municípios estudados (CMD, AM e DJ) existe um escritório da EMATER e no mínimo um técnico atuando e, como exposto anteriormente a empresa é a única que emite a DAP nestes municípios. Portanto, a empresa é responsável por fazer as orientações e acompanhamentos técnicos com as famílias e também por auxiliar nas burocracias.

Segundo os técnicos da empresa, para a retirada da DAP são solicitados para as famílias os seguintes documentos: a) Documentos pessoais (Carteira de Identidade, CPF e Certidão de Casamento); b) Comprovante de renda (Declaração de renda a qual comprove que $50 \%$ da renda total da família sejam por meio de atividade rural); e c) Documentação da terra (contrato de compra e/ou documento de posse). O segundo e o terceiro documento dependem de auxílio técnico: se não houver uma pessoa capacitada para auxiliar a família provavelmente não saberá a forma de conseguir. E depois a família conseguindo ganhar a chamada pública, terá que emitir uma nota fiscal no número da DAP tirada. Para Azevedo (2014, p. 33), todo esse processo burocrático "pode ser um empecilho, visto que, 37\% dos agricultores não sabem ler e nem escrever".

Em Conceição do Mato Dentro, Alvorada de Minas e Dom Joaquim, muitas famílias ainda não tiraram a DAP, demonstrando que a declaração é também um desafio a ser superado para participação das famílias ao PNAE, tanto na atuação dos técnicos que emitem a declaração, quanto nos limites estruturais das condições da agricultura familiar tratadas no próximo tópico. As famílias que possuem DAP de Alvorada de Minas e Dom Joaquim não chegam a $50 \%$, Conceição do Mato Dentro foi o único que esteve na faixa dos $50 \%$, o que implica que os outros $50 \%$ da agricultura familiar do município nunca puderam participar do PNAE e nem das demais políticas destinadas a este grupo social (Tabela 2).

Tabela 2 - Quantidade de DAP em CMD, AM e DJ no ano de 2016.

\begin{tabular}{|l|l|l|l|}
\hline Município & No de Família $^{\text {No de DAP }}$ & $\%$ \\
\hline CMD & 1003 & 526 & $52 \%$ \\
\hline AM & 600 & 194 & $32 \%$ \\
\hline DJ & 550 & 111 & $20 \%$ \\
\hline
\end{tabular}

A atuação dos técnicos de Ater's como a EMATER, os técnicos da Cáritas e outras empresas e ONG's que fazem este tipo de trabalho, é um tema frequentemente discutido por estudiosos do desenvolvimento rural territorial. Trata-se de uma atuação considerada central para a materialização do desenvolvimento de bases sustentáveis. Por exemplo, na região estudada, a chegada dos técnicos da Cáritas foi importante, de acordo com um Agricultor de $\mathrm{CMD}^{1}$ (2017) "melhorou muito depois que a Cáritas chegou, agora nós estamos produzindo alimentos agroecológicos". Uma agricultora de DJ disse que "depois que juntou a Cáritas e a EMATER para nos amparar, estamos tendo um suporte maior e força pra produzir" (Agricultora familiar de $\mathrm{DJ}^{3}$, 2017).

\section{Logística}

A logística também apareceu para as famílias de Conceição do Mato Dentro e Dom Joaquim como um desafio. E como indicam os estudos bibliográficos, a dificuldade com a logística é algo que faz parte da 
dificuldade da agricultura familiar em todo o Brasil. Mesmo as organizações (Cooperativas e Associações) sofrem com a falta de transporte. Camargo, Baccarin e Silva (2012, p. 10), argumentaram que a:

[...] logística é um dos maiores gargalos enfrentados pelos agricultores, já que a maior parte das associações e cooperativas de produtores familiares não tem caminhão ou outro veículo para transportar sua produção, e terceirizar o frete diminui sua renda.

Em Conceição do Mato Dentro, existem comunidades rurais localizadas muito distantes da sede municipal, o que tende a dificultar ainda mais a translocação dos alimentos. Neste quesito, chama a atenção o caso de Alvorada de Minas: no município a prefeitura fazia o transporte dos alimentos, e as famílias os deixavam embalados prontos para entrega e o motorista da prefeitura buscava e levava para o local de armazenamento.

Iniciativas como a que havia na prefeitura de Alvorada de Minas mostra que é possível superar o desafio da logística. Outra opção seria descentralizar os locais de recebimento dos alimentos, pois muitos dos alimentos vão para a sede municipal e depois retornam para as escolas da zona rural. Se fizessem como Castro e Bombardi (2013) indicaram, cada comunidade, ou comunidades rurais próximas poderiam ter um ponto de recebimento. Assim, haveria maior facilidade para as famílias e um gargalo importante poderia ser superado. Segundo as autoras, seria a "regionalização das entregas, ou seja, o produtor realiza a entrega nas escolas que estiverem mais próximas a ele, evitando dessa forma grandes deslocamentos e, consequentemente, aumento dos custos" (CASTRO; BOMBARDI, 2013, p.13).

\section{MUdANÇA da GESTÃo MUNICIPAL}

Este foi um desafio encontrado no município de Alvorada de Minas. A cada 4 anos são realizadas as eleições municipais em todo Brasil, quando muitas vezes muda-se a gestão. Quando a nova gestão é continuidade da antiga, os trabalhos tendem a continuar, mas quando são construídas rivalidades nos processos eleitorais, os projetos costumam ser interrompidos. Quando isso acontece, muitas vezes é realizado o remanejamento do quadro burocrático da prefeitura, ou seja: as pessoas são trocadas de cargos e com isso as responsabilidades também são alteradas.

O cenário de Alvorada de Minas passou por algumas alterações a partir das eleições de 2016. Este fato foi registrado durante o trabalho de campo em setembro de 2017. No ano de 2017, iniciou a atuação de uma nova gestão e parte dos responsáveis pela execução do PNAE na prefeitura foram remanejados de cargos ou demitidos, o que prejudicou o andamento do programa no município. De acordo com uma Agricultora de $\mathrm{AM}^{2}$ (2017) "antes tinha a moça que trabalhava na secretaria de agricultura que buscava os alimentos; agora não tem ninguém pra buscar", outra agricultora disse que "a prefeitura não quer mais ceder o transporte, dizendo que não tem dinheiro" (Agricultora de AM" ${ }^{1}$ 2017).

Em uma oficina no município "Oficina Intercomunitária de Comercialização da Agricultura Familiar de Alvorada de Minas" promovida pela Cáritas, às famílias foram questionadas sobre quais eram as dificuldades que elas tinham no fornecimento de alimentos para o PNAE, os (as) agricultores (as) que participavam do programa disseram que até 2016 não tinham problemas, pois havia o suporte da prefeitura, mas que em 2017 até o dia da oficina que ocorreu no mês de setembro, a nova gestão da prefeitura ainda não havia aberto a chamada pública.

Isso indica que a mudança na gestão municipal pode também comprometer a participação das famílias no programa, pelo menos no primeiro ano de gestão, até que os novos responsáveis passem a dominar os processos do PNAE. Alexandre et al. (2016) alegaram que a descontinuidade dos processos devido a mudança na gestão local provoca o enfraquecimento das dinâmicas locais, influenciando de modo negativo a execução da Lei $\mathrm{n}^{\mathrm{o}} 11.947 / 2009$.

Entre as possibilidades de superar esse desafio está a formação de servidores (as) efetivos (as) aos cargos, por exemplo, o caso do (a) nutricionista concursado (a) da prefeitura. Assim por mais que a gestão municipal mude o (a) nutricionista permanece no serviço público, evitando desvios e desencontros na gestão do PNAE. Segundo Corrêa et al. (2017, p. 570) "a existência do vínculo permanente com a EEx, por meio de concurso público, aumenta a estabilidade do profissional e a possibilidade de desenvolver ações em caráter permanente e de forma contínua". Por isso, é fundamental o envolvimento desses servidores, para que deem continuidade na execução do programa.

Contudo, os desafios identificados para a participação da agricultura familiar de Conceição do Mato Dentro, Alvorada de Minas e Dom Joaquim ao PNAE, como visto foram os mesmos presentes em outras pesquisas em regiões diferentes do Brasil. Ressalta-se, porém, que são desafios que podem ser superados, por meio de capacitações, troca de experiências, 
sensibilidade e responsabilidade por parte dos gestores públicos e dos técnicos. Dessa forma, a atuação desses sujeitos é a principal questão que compõe estes desafios.

\section{LIMITES}

Neste trabalho os limites foram entendidos como limitações que não se resolvem em âmbito local, pois esbarram em questões estruturais e complexas, profundamente relacionadas à formação histórica da sociedade brasileira. Os limites foram divididos em dois: o recurso financeiro do PNAE e as condições estruturais da agricultura familiar.

\section{Recurso Financeiro}

Conforme o levantamento da implementação do PNAE em Conceição do Mato Dentro, Alvorada de Minas e Dom Joaquim, municípios pequenos possuem a demanda da alimentação escolar também pequena, pois normalmente é proporcional ao tamanho da população. Entretanto, é em municípios menores que se encontra uma maior concentração da população rural. Nesse sentido, a demanda da alimentação escolar pode ser considerada um fator limitante para o desenvolvimento do PNAE na região estudada, mesmo porque, conforme o FNDE, o recurso financeiro destinado às Unidades Executoras é de acordo com o número de alunos, categorias de ensino e dias letivos. Sendo assim, quanto menos alunos, menor é o recurso que o FNDE encaminha para alimentação escolar.

Segue o exemplo de Alvorada de Minas: o repasse financeiro que o FNDE realizou em 2015 para complementar o recurso da prefeitura destinado à alimentação escolar foi de $\mathrm{R} \$ 36.720,00$, deste valor, no mínimo $30 \%$ são obrigados a serem destinados para aquisição de alimentos da agricultura familiar. Neste caso, o percentual mínimo daria apenas R $\$ 11.016,00$, supondo que uma família agricultora participasse do programa, a renda mensal desta família seria equivalente a $\mathrm{R} \$ 918,00$, ou seja, menor do que um salário mínimo.

Uma saída para esse limitante seria utilizar $100 \%$ do recurso que o FNDE destina ao PNAE para a aquisição direta de alimentos da agricultura familiar. Novamente utilizando o município de AM como exemplo: a prefeitura chegou a adquirir em 2014, 90\% do recurso na aquisição alimentos direto da agricultura familiar, e o valor total da chamada pública foi de $\mathrm{R} \$ 49.430,04$. Contudo, o valor ainda foi considerado baixo, pois cada família poderia elaborar seu projeto de venda equivalente de até $\mathrm{R} \$ 20.000,00$, ou seja, duas famílias poderiam cumprir com quase toda a demanda apresentada na chamada pública (Resolução no $26 \mathrm{CD} / \mathrm{FNDE} / 2013$ ). De qualquer maneira, não deixa de ser uma saída plausível para que mais famílias do município possam participar do programa.

Uma outra possibilidade para minimizar esse problema seria somar o recurso suplementar que o FNDE disponibiliza para o PNAE com o da unidade executora (prefeitura e/ou estado). Nesse sentido, destaca-se Conceição do Mato Dentro como exemplo. O valor da chamada pública da prefeitura de Conceição do Mato Dentro em 2016 foi de R \$ 410.090,94 (a soma total dos valores de cada item). Considera-se um valor alto, quando comparado ao recurso do FNDE em 2015 que foi na ordem de $\mathrm{R} \$ 110.660,00$

Nota-se que comparando o valor total da chamada pública de $2016 \mathrm{com}$ o que a prefeitura recebeu do FNDE em 2015, a prefeitura somou recursos próprios com o do FNDE para a aquisição de alimentos da agricultura familiar, ultrapassando os $100 \%$. Foram 10 famílias que pleitearam a entrega dos alimentos em 2016, ainda que, com o valor da chamada pública o número de famílias participantes poderia ser o dobro. Se cada família pode entregar no máximo, $\mathrm{R} \$ 20.000,00$ por DAP, significa que para cumprir com toda demanda da chamada pública da prefeitura seria necessário a participação de no mínimo 20 famílias.

Segundo o Censo Agropecuário (2006) e os dados primários da pesquisa, existem 1003 unidades familiares rurais em Conceição do Mato Dentro, $600 \mathrm{em}$ Alvorada de Minas e $550 \mathrm{em}$ Dom Joaquim. De acordo com as informações, o recurso disponível para o PNAE nestes municípios não chega a possibilitar a participação de $5 \%$ da agricultura familiar dos municípios. Em Conceição do Mato Dentro, onde o valor do recurso foi maior, se 20 famílias participassem fornecendo o valor máximo por DAP, comparando às 1003 unidades familiares existentes no município, as 20 famílias participantes do programa corresponderia a apenas $2 \%$ da agricultura familiar do município. Vale salientar, todavia, que o programa vai muito além das questões econômicas, conforme será observado no tópico acerca das potencialidades do PNAE.

Nos três municípios investigados os números apresentados foram os das escolas e/ou unidades de ensino municipais, os quais foram centralizados pelas prefeituras. Desta forma, buscou-se também fazer o levantamento dos recursos que as escolas estaduais receberam para fornecerem a alimentação escolar, com a intenção de saber, se somando os recursos, poderia aumentar o número de participação das famílias agricultoras. Neste caso, destaca-se novamente Conceição do Mato Dentro como exemplo, pois diante dos três 
municípios, ele é o que possui mais escolas da rede estadual e também mais alunos (Quadro 2).

Quadro 2 - Recurso destinado pelo FNDE para a alimentação nas escolas estaduais de CMD.

\begin{tabular}{|c|c|c|c|}
\hline MUNICÍPIO & $\mathbf{N}^{\circ}$ DE ESCOLAS & $\mathbf{N}^{\circ}$ DE ALUNOS & $\begin{array}{r}\text { VALOR } \\
\text { ALIM. ESCOLAR } \\
\end{array}$ \\
\hline $\begin{array}{l}\text { CONC. DO MATO DEN- } \\
\text { TRO }\end{array}$ & 10 & $\begin{array}{r}4000 \text { (aproximada- } \\
\text { mente) }\end{array}$ & \\
\hline \multicolumn{3}{|r|}{ TOTAL RS } & $425.376,00$ \\
\hline \multicolumn{3}{|c|}{ 30\% Agricultura Familiar R\$ } & $127.612,80$ \\
\hline
\end{tabular}

Fonte: Adaptado pela autora (Superintendência Regional de Ensino de Diamantina $-\mathrm{MG}, 2017)$.

Conforme os valores totais (soma total do recurso e soma do valor dos $30 \%$ ), nem mesmo somando o recurso das escolas estaduais com o das municipais, seria possível que a participação das famílias atingisse os 5\% de toda a população de famílias agricultoras dos municípios. No entanto, em Conceição do Mato Dentro, para a entrega de alimentos nas escolas municipais, no mínimo, 20 famílias cumpririam com os itens da chamada pública. Juntando com as escolas estaduais, seriam 40, isto é, 40 de 1003.

Os resultados desta pesquisa vão ao encontro do trabalho de Abreu (2014) sobre a implementação do PNAE em municípios pequenos. Segundo a autora, municípios de pequeno porte possuem sérias limitações, dentre elas está o recurso e a quantidade de famílias.

No debate sobre as contribuições do PNAE para a melhoria das condições de vida no meio rural, para o desenvolvimento local e dos agricultores familiares, é preciso ponderar os limites do programa em municípios de pequeno porte (que representam $70,7 \%$ dos municípios do país), onde o número de agricultores familiares tende a ser alto e a capacidade de inclusão comercial do Programa é pequena (ABREU, 2014, p. 168).

Nesse sentido, o que a realidade dos municípios estudados mostra é que o recurso financeiro é um grande limitante para a ampla participação da agricultura familiar ao PNAE e que esta limitação não se resolve localmente, porque não cabe aos gestores municipais resolver. Trata-se, na verdade, como se verificou, de um limite do próprio programa enquanto política pública. Daí a importância de se pensar em instrumentos de política pública adequados, tornando os recursos compatíveis, visando a objetivos socialmente construídos.

\section{CONDiÇões ESTRUTURAIS}

Além das limitações de participação da agricultura familiar no PNAE encontram-se as condições estruturais. Tais condições são consequências históricas do desenvolvimento rural pautado na grande propriedade monocultora, destinada à exportação. No Brasil, a modernização da agricultura se "sustentou nas grandes empresas e no benefício da acumulação do capital privado" (CARNEIRO, 1997, p. 73). Esse processo acentuou a histórica desigualdade social existente no país.

No estudo que Grisa (2017) fez sobre o Pronaf e PAA, a autora se deparou com algumas limitações de participação das famílias aos programas, dentre as quais destacam-se: "falta de informação, ausência de documentação pessoal, ausência da DAP para ingressar no programa, falta de ou pouca terra, dificuldades organizacionais, e limitações de infraestruturas (estradas, acesso à água, ausência de equipamentos)". Essas limitações correspondem às mesmas observadas na região estudada quanto ao acesso e participação dos agricultores ao PNAE.

Nos três municípios foi possível identificar que as condições de ocupação, acesso e uso da terra também são fatores limitantes para a participação das famílias no PNAE e em outras políticas públicas. Afinal, muitas famílias agricultoras não possuem a documentação de regularização das terras em que vivem. No geral, são lotes pequenos, existindo na região muitos vestígios de quilombos. Acredita-se que muitas comunidades rurais são quilombolas, embora poucas tenham esse reconhecimento ou se reconheçam como tal (GUSTIN, et al. 2015). Com o projeto Rio-Minas o acesso e permanência na terra ficou ainda mais difícil, tendo em vista a política de expropriação e privatização da terra e dos fragmentos florestais praticados pela empresa, o que tem prejudicado a produção da agricultura familiar na região (PEREIRA; BECKER; WILDAGHEN, 2013).

Essa é uma realidade que não diz respeito somente a Conceição do Mato Dentro, Alvorada de Minas e Dom Joaquim, mas também a outras regiões e à agricultura familiar brasileira como um todo. Comparada ao agronegócio ou aos grandes proprietários de terra, a agricultura familiar ocupa apenas $24,3 \%$ das áreas agricultáveis no país, mesmo sendo $84,4 \%$ da população que vive no campo (EMBRAPA, 2014). Desses $84,4 \%$ mais de $70 \%$ ocupam áreas menores do que 2 hectares (Censo Agropecuário, 2006).

A agricultura familiar já demonstrou ter maior eficiência em diversos 
aspectos comparados ao agronegócio, seja na geração de empregos, seja na produção de alimentos e até mesmo na geração de renda (IPEA, 2011). No entanto, a hegemonia das elites agrárias no Brasil, vigente desde os tempos coloniais ainda se reproduz fortemente, seja no controle do Estado, por meio da atuação da bancada ruralista, seja no controle da propriedade de terras, o que se verifica com a atual estrutura fundiária.

Segundo Girardi (2009, p. 02), a questão agrária é “compreendida como o conjunto de problemas inerentes ao desenvolvimento do capitalismo no campo", e estes problemas devem ser apontados, discutidos e solucionados a partir do movimento histórico da luta pela terra.

No entanto, em que pese a existência de dois planos nacionais de Reforma Agrária, nenhum deles foi executado, o que pode explicar até hoje a reprodução das desigualdades sociais no campo e a permanência do latifúndio na formação histórica da sociedade brasileira. Por isso, vale destacar que atualmente existem no Brasil cerca de 35 mil latifúndios improdutivos ao lado da existência de 4,5 milhões de famílias sem terra (REIS, 2011). Pela CF/1988 a terra deve cumprir uma função social (moradia, alimentação, preservação ambiental) caso não esteja cumprindo nenhuma dessas funções, o proprietário estará cometendo um ato inconstitucional e deve ser penalizado por isso.

Portanto, a reforma agrária, além de uma dívida histórica, é uma medida necessária e eficiente de resolver o problema da discrepante desigualdade na divisão de terras, mas que deve acontecer ao lado de políticas públicas territoriais como as que foram desenvolvidas nos últimos anos e com a orientação para uma produção sustentável (orgânica e agroecológica). Carneiro (1997) apontou que uma reforma agrária bem planejada e estruturada seria fundamental para proporcionar maior acessibilidade da agricultura familiar ao Pronaf, o que poderia aumentar também a chance de acesso às demais políticas públicas, como por exemplo, o PNAE.

Com o problema da divisão de terras resolvido, facilitaria para as famílias terem a documentação de regularização das terras onde vivem e, assim, terem acesso a DAP e força maior para encarar empreendimentos como o Minas-Rio. Famílias com terras regularizadas, produzindo e participando de políticas públicas, teriam melhores condições para resistirem em suas terras; elas estariam em condição de disputar os recursos com o empreendimento e até, como já foi visto em outras regiões, poderiam não deixar que eles se instalassem no território. Há exemplos de comunidades que se organizaram e conseguiram a proibição da instalação de empreendimentos minerários: na Argentina a organização popular conseguiu proibir a instalação da mineradora Meridian Gold; e no Peru, o direito de exploração mineral da empresa Manhattan Minerals Corp., foi cassado, resultados da organização popular (MILANEZ; LOSEKANN, 2016).

Além da problemática envolvendo a questão agrária, existe também a disputa pelos demais recursos naturais, como a água. Galizoni et al (2008) ao analisar casos no Alto Jequitinhonha, região vizinha à área de estudo da presente pesquisa, aborda como os agricultores garantem sua reprodução social diante dos limites do ambiente. Segundo os autores, a escassez de água pode ocorrer por dois motivos: os naturais (existem regiões geográficas que passam por períodos longos de estiagem), e por ações antrópicas (quando as indústrias contaminam a água ao ponto de não ser mais segura para o consumo dos seres vivos, ou quando empreendimentos demandam de uma quantidade excessiva de água, utilizando mais água do que a natureza dispõe, sobrecarregando a capacidade hídrica de uma bacia). As duas situações se tornam limitantes para a produção da agricultura familiar, com importantes ressalvas quanto a escassez natural, pois as famílias que vivem há tempos nessas regiões, já desenvolveram técnicas, selecionaram espécies de plantas e animais que melhor se adaptam a esta realidade, criando um certo tipo de convívio com o semiárido (GALIZONI et al., 2008).

No caso da escassez pelas atividades antrópicas analisadas nesta pesquisa, muitas vezes as famílias não compreendem o acontecimento. Em uma comunidade rural em Alvorada de Minas, uma agricultura produtora de leite, teve que diminuir o rebanho pela metade devido à escassez de água que afeta diretamente a produção do leite e seus derivados. Para esta agricultora a escassez de água está relacionada a questões divinas dos "fins dos tempos". Ou seja, ela não relacionou a escassez de água com a atividade minerária, fazendo orações para que a água volte.

Outro exemplo a ser citado, foi o crime em Mariana. Para as famílias que viviam as margens do Rio Doce e utilizavam as águas para irrigação e pesca, a lama que atingiu o rio e contaminou as águas modificou totalmente a dinâmica de produção e sobrevivência dessas famílias; elas eram acostumadas com a abundância, tinham uma interação forte com o rio que foi interrompida por um crime de responsabilidade da empresa Samarco (MILANEZ; LOSEKANN, 2016). Guardadas as devidas proporções, é o que também parece ocorrer em Conceição do Mato Dentro, Alvorada de Minas e Dom Joaquim.

Para Galizoni et al. (2008, p. 148), “a escassez de água para produção 
e criação é um fator de empobrecimento para famílias". As famílias que não conseguem produzir, seja para comercialização ou para a subsistência, tendem a ficarem empobrecidas, em uma situação de maior vulnerabilidade social.

Portanto, para as famílias que sofrem com a escassez de água, o acesso e participação no PNAE são limitados: o programa não consegue contemplar as famílias que vivem nesta situação. Para as que moram em regiões onde estas são as condições naturais, existem outras políticas como o PAA Leite, o Programa de Cisternas, que contemplam as condições de vida dessa população. No caso da região de estudo (CMD, AM e DJ) e de outros lugares impactados por grandes empreendimentos, não existem políticas públicas especificas.

Como se pode observar as limitações estão relacionadas à estrutura política econômica e social do país. Enquanto as bases estruturais forem a exploração a serviço do mercado mundial, grupos sociais como o da agricultura familiar permanecerão marginais na sociedade brasileira e limitados quanto ao acesso às políticas públicas que, em tese, lhes seriam destinadas. As limitações de participação da agricultura familiar ao PNAE demonstram isso.

\section{Potencialidades}

"Sem a horta eu teria que ir pra cidade" (Agricultora familiar de DJ3, 2017).

O PNAE é um programa de política pública que apresenta desafios e limites para a participação da agricultura familiar. Alguns aspectos devem ser revistos e incrementados ao programa. Todavia, apesar dos desafios e limitações apresentados anteriormente, não há dúvidas de que se trata de um programa cujos resultados são positivos para agricultura familiar e para o desenvolvimento rural de base territorial.

Para Alexandre et al. (2017, p. 1050) este apoio que o programa tem dado à agricultura familiar,

\section{[...] representa o resgate do patrimônio alimentar, reintegrando as dimensões da produção e do consumo de alimentos, contribuindo para a redução da iniquidade, promovendo a geração de renda para os agricultores familiares e sinaliza uma relevante estratégia de redução da pobreza e do êxodo rural.}

Além desses potenciais, a participação da agricultura familiar no fornecimento de alimentos para merenda escolar incentiva os hábitos de uma alimentação mais saudável baseada no consumo dos alimentos locais (SOUZA-ESQUERDO; BERGAMASCO, 2014). Essa política tem, pois, o potencial de contribuir também para a construção da política nacional de segurança alimentar e nutricional do país, primando pela soberania, no âmbito das políticas sociais.

\section{Valorização da Agricultura Familiar}

As potencialidades indicadas pela teoria foram as mesmas relatadas pelas famílias pesquisadas. "É uma oportunidade aos agricultores" (Agricultora familiar de $\mathrm{AM}^{2}$, 2017). "O PNAE ajuda muito as pessoas que vivem na roça" (Agricultor familiar de $\left.\mathrm{CMD}^{1}, 2017\right)$. "O PNAE chegou valorizando a mercadoria da gente" (Agricultora familiar de $\mathrm{DJ}^{2}$, 2017).

As famílias entrevistadas, que já fornecem alimentos ao PNAE, avaliam positivamente o programa e sentem que suas produções estão sendo valorizadas. Além dos fatores relacionados à autoestima, destacam-se o orgulho de produzirem alimentos saudáveis, o conhecimento de quem serão os consumidores e a preocupação com a entrega de um alimento de qualidade. "Tem alimento bom para crianças nas escolas, sem veneno" (Agricultor familiar de CMD", 2017). "Eu tenho orgulho do que eu passo para frente [...], as crianças nas escolas estão comendo comida saudável" (Agricultora familiar de $\mathrm{DJ}^{3}$, 2017). "Os pais que tem filhos na escola conhecem a maior parte dos alimentos que os filhos estão ingerindo na escola, e que são de qualidade" (Agricultora familiar de $\mathrm{DJ}^{2}, 2017$ ).

Isso gera uma aproximação dos agricultores com os consumidores, criando uma relação de confiança e eliminando atravessadores, tendo assim uma distribuição mais justa da renda gerada na produção de alimentos da agricultura familiar, que antes ficava em boa parte nas mãos de outros sujeitos (SAMBUICHI et al., 2014 ). Com isso, a confiança gerada nessa aproximação do campo com a cidade também estimula outros mercados locais, de venda direta, abrindo outros canais de comercialização para a produção da agricultura familiar (SAMBUICHI et al., 2014 ).

\section{Organização Produtiva}

A pesquisa indica que existem famílias que, se não estivessem participando do PNAE, já teriam migrado para a cidade. A garantia da venda e do preço atua como um estímulo para que os agricultores produzam. "Posso produzir porque sei que vou vender" (Agricultora familiar de DJ, 2017). "A gente 
não fica na mão do comerciante" (Agricultora familiar de DJ, 2017). "Às vezes a gente plantava uma horta só para o consumo, para galinha e para o porco, agora se você vai vender cem pés de alface você produz duzentos, que ai fica cem pra gente" (Agricultora familiar de $\mathrm{DJ}^{3}$, 2017).

A motivação ao produzir tendo a garantia e segurança da venda faz com que os agricultores busquem outros mercados, diversificando a produção. Em Dom Joaquim parte das famílias que participam do PNAE iniciaram uma feira-livre aos sábados na praça central do munícipio. Para tanto, contam, com o apoio da EMATER e da Cáritas.

$\mathrm{O}$ acesso da agricultura familiar a esse tipo de mercado local garante não só a segurança e a soberania alimentar dos alunos das escolas, mas também da população local, que passa a conhecer a procedência dos alimentos que consome. Portanto, considera-se que o PNAE seja também um estímulo para a participação da agricultura familiar em outros mercados.

Para as famílias produzirem e comercializarem elas precisam de organização, devendo controlar o que vão produzir, em qual período e quantidade, de maneira que mantenham sempre a mesma qualidade dos alimentos. Como foi dito por uma agricultora, "o PNAE é ótimo para quem tem responsabilidade" (Agricultora familiar de AM, 2017). Nesse sentido, o programa exige que as famílias tenham organização produtiva, incentivando que elas tenham o controle de todos os processos.

\section{GERAÇão de RENDA E EMANCIPAÇão SOCIAL}

Com a aquisição dos alimentos produzidos localmente, o PNAE fomenta também a economia do município, pois se a população local tem dinheiro, muito provável que o gaste no próprio município, comprando desde produtos básicos até mercadorias, dinamizando a economia local. . De uma maneira geral, as receitas geradas pela agricultura familiar, seja através de suas vendas ou através das transferências (aposentadorias, pensões, Bolsa Família, programas mais específicos e outros) não são percebidas pelo senso comum, mas o fato é que a relação de trocas campo-cidade é favorável às cidades.

A geração de renda pode ser considerada uma das consequências de todo o potencial que o PNAE apresenta, mas não pode ser o foco central das discussões. É verdade que o PNAE gera renda, no entanto o recurso do programa é limitado, de modo que não daria para que todas as famílias agricultoras de um município participassem do programa.

Entre as 5 famílias entrevistadas que já participam do PNAE, 4 são as mulheres que estão a frente da organização e trabalho para o PNAE. Estudando o empoderamento das mulheres que participam do PNAE em Viçosa (MG), Barbosa (2017) comparou as mulheres agricultoras que participam do programa com as que não participam. Segundo a autora, o ponto mais divergente entre elas é a renda, capaz de influenciar as demais áreas da vida. Para Barbosa (2017, p. 56) a falta de renda limita o acesso a bens e serviços de qualidade, "assim tais mulheres podem ter seu processo de empoderamento comprometido. Além disso, não demonstram preocupação com sua participação social, tendo mais dificuldade de se expressarem”. Já as mulheres que participam do PNAE “entendem a importância da participação social, principalmente para proporcionar o atendimento das demandas comunitárias e superar as desigualdades enfrentadas" (BARBOSA, 2017, p. 57).

Acredita-se que o PNAE funcione como uma motivação inicial para as famílias, contribuindo para emancipação social. A partir daí as famílias conseguem autonomia econômica advinda de seu trabalho, participação política e identidade cultural e regional, conforme foi possível perceber nos relatos das famílias entrevistadas.

\section{CONSIDERações Finais}

O PNAE é um programa estruturante, capaz de transformar múltiplos aspectos das realidades vivenciadas pelas famílias que dele participam. $\mathrm{Na}$ pesquisa que se conclui observou-se o aumento na autoestima das famílias, relacionado ao orgulho que se tem do que se produz; a organização produtiva; a participação em outros mercados; a geração de renda; a participação feminina; a segurança alimentar. Enfim, são múltiplos aspectos que permitem afirmar que o PNAE é capaz de contribuir para a transformação da realidade da agricultura familiar brasileira.

Para tanto, os desafios estão postos e é necessário um acompanhamento técnico nas prefeituras e escolas estaduais na execução do programa, para que essas Unidades Executoras consigam adquirir 100\% do recurso em alimentos da agricultura familiar. Destaca-se ainda, como uma conclusão importante desta investigação, a necessidade de expansão da agricultura familiar no interior dos estados (onde está a maior concentração de agricultores), considerando suas potencialidades de abastecer e sustentar a existência da população urbana que vive nas regiões metropolitanas do país. Isso poderia ser garantido com a expansão do Programa, visando a produção sustentada de alimentos saudáveis, livres de agrotóxicos.

Vale ressaltar também, conforme a pesquisa demonstrou que sem o auxílio técnico dos extensionistas na elaboração dos projetos de venda e demais 
trâmites burocráticos os agricultores familiares não conseguem participar do PNAE. Isso porque, considerando a realidade do meio rural, onde existem ainda muitos analfabetos, os processos burocráticos intrínsecos ao programa não são inclusivos. Desta forma, o trabalho e o compromisso dos técnicos das ATER's em fazer com o que a participação da agricultura familiar aconteça são fundamentais, pois sem este tipo de trabalho as famílias não ficam sequer sabendo da existência do programa.

Os impactos e consequências da mineração são inevitáveis e prejudiciais ao acesso e participação das famílias ao PNAE. Conforme a análise dos dados indicou, as famílias foram atingidas pela instalação do Projeto MinasRio, ficando sem água e sem terra. Portanto, mesmo que o programa seja implementado com sucesso, as famílias atingidas pela mineração terão dificuldades porque mal conseguem garantir atualmente a produção para sua própria subsistência, que dirá fornecer ao PNAE. O processo será seletivo e restrito às famílias que sofreram menos impactos. Assim, a agricultura familiar que historicamente luta e resiste com a chegada do empreendimento minerário vê-se sujeitada aos novos e grandes desafios de permanência no campo.

\section{REFERÊNCIAS}

ABREU, K. D. R. A implementação do Programa Nacional de Alimentação Escolar (PNAE) em municípios de pequeno porte: implicações práticas e teóricas. 2014. 183 f. Dissertação (Mestrado em Administração Pública e Governo) - Fundação Getulio Vargas, São Paulo, 2014.

ALEXANDRE, V. P.; GOMES, L. O. F.; SILVA, S. U.; ALMEIDA, G. M.; MARTINS, K. A.; MONEGO, Estelamaris Tronco; SOUZA, L. M.; CAMPOS, M. R. H.. Do campo à escola: compra de alimentos da agricultura familiar pelo Programa Nacional de Alimentação Escolar em Territórios da Cidadania de Goiás. Segur. Aliment. e Nutr., Campinas, v.23, n.esp., p.1049-1064, dez. 2016.

AZEVEDO, R. F. O. A relação entre o PNAE e a agricultura familiar: virtudes e problemas de gestão. Disponível em: < http://www.cchla. ufrn.br/dpp/gpp/TCC/2014.1/arquivos_downloads/AZEVEDO,Raphael_ Fernandes_Oliveira_de._A_Rela\%C3\%A7\%C3\%A3o_Entre_o_
PNAE_e_a_Agricultura_Familiar..Virtudes_e_Problemas_de Gest\%C3\%A3o.pdf> Acesso em: 19 set. 2017.

BARBOSA, T. L. O processo de empoderamento da mulher rural e o Programa Nacional de Alimentação Escolar (PNAE): e o caso de ViçosaMG. Dissertação de mestrado, UFV, Viçosa. 2017. p. 80.

BELLEZE, G. Comunidades rurais tradicionais atingidas pelo projeto de mineração Minas-Rio: Afinal, desenvolvimento para quem? Dissertação de mestrado, UNIFEI, Itajubá. 2017. Disponível em: $<\underline{\text { https:// }}$ nucleotravessia.unifei.edu.br/wp-content/uploads/2017/05/GabrielaBelleze-DTECS.pdf> Acesso em: 08 out. 2017.

BRASIL. Lei no 11.947, de 16 de junho de 2009. Disponível em: < http:// www.planalto.gov.br/ccivil_03/_ato2007-2010/2009/lei/111947.htm> Acesso em: 30 dez. 2016.

CAMARGO, R. A. L.; BACCARIN, J. G.; SILVA, D. B. P. O papel do Programa de Aquisição de Alimentos (PAA) e do Programa Nacional de Alimentação Escolar (PNAE) no fortalecimento da agricultura familiar e promoção da segurança alimentar. Temas de Administração Pública. v. 8, n. 2, 2013.

CARNEIRO, M. J. Política pública e agricultura familiar: uma leitura do Pronaf. Estudos Sociedade e Agricultura, 8, abril 1997: 70-82. Disponível em: $<$ http://bibliotecavirtual.clacso.org.ar/ar/libros/brasil/cpda/estudos/oito/ carneiro8.htm> Acesso em: 21 set. 2017.

CASTRO, T. P. ; BOMBARDI, L.M. PNAE: Potencialidades e limites para contribuição no processo de territorialização camponesa. Disponível em: $<$ http://www.uniara.com.br/legado/nupedor/nupedor_2014/ Arquivos/01/1A/11_Terena\%20Castro.pdf $>$ Acesso em: 19 set. 2017.

CORRÊA, R. S.; ROCKETT, F. C.; ROCHA, P. B.; SILVA, V. L.; OLIVEIRA, V. R. Atuação do Nutricionista no Programa Nacional de Alimentação Escolar na Região Sul do Brasil. Ciência \& Saúde Coletiva, 22(2): 563-574, 2017. 
FAZENDA, I. C. A.; JOSÉ, M. A. M.; SANTOS, C. A. M. Formar Pesquisadores Interdisciplinares. Revista Ciências Humanas - Educação e Desenvolvimento Humano - UNITAU, Taubaté/SP - Brasil, v. 9, n 1, edição 16, p. 62 - 69, Junho 2016. Disponível em: $<$ http://www.rchunitau. com.br/index.php/rch/article/view/276/185> Acesso em: 28 nov. 2016.

FUNDO NACIONAL DESENVOLVIMENTO DA EDUCAÇÃO - FNDE. Aquisição de produtos da agricultura familiar para a alimentação escolar. Disponível em: <goo.gl/1dXozy> Acesso em: 20 nov. 2016.

FUNDO NACIONAL DESENVOLVIMENTO DA EDUCAÇÃO - FNDE. Cartilha Nacional da Educação Escolar. Disponível em: $<$ http://www.fnde.gov.br/arquivos/category/116-alimentacaoescolar?download=9572:pnae-cartilha-2015> Acesso em: 20 abr. 2016.

Sobre o PNAE. Disponível em: $<$ http://www. fnde.gov.br/programas/programas-suplementares/pnae-sobre-o-programa/ pnae-sobre-o-pnae> Acesso em: 20 mar. 2018.

Dados da Agricultura Familiar. Disponível em: $<$ http://www.fnde.gov.br/programas/pnae/pnae-consultas/pnae-dadosda-agricultura-familiar> Acesso em: 20 mar. 2018.

GALIZONI, F. M.; R., E. M.; LIMA, V. M. P.; SANTOS, I. F. ; CHIODI, R. E.; LIMA, A. L. R.; AYRES, E. C. .B.. Hierarquias de Uso de Águas nas Estratégias de Convívio com o Semi-Árido em comunidade rurais do Alto Jequitinhonha. Revista Econômica do Nordeste, Fortaleza, v. 39, $\mathrm{n}^{\mathbf{o}}$ 1, jan-mar. 2008. $133-152$.

GIRARDI, Eduardo Paulon. Atlas da Questão Agrária Brasileira. Disponível $\mathrm{em}:<$ http://www2.fct.unesp.br/nera/atlas/questao_agraria.htm $>$ Acesso em: 30 jan. 2018

GRISA, C. A agricultura familiar nas políticas para a agricultura familiar. DELGADO, G. C. Bergamasco, Sonia Maria Pessoa Pereira (orgs.) Agricultura familiar brasileira: desafios e perspectivas de futuro. Brasília: Secretaria Especial de Agricultura e do Desenvolvimento Agrário, 2017.
GRISA, C.; SCHNEIDER, S.. Três geracõos de políticas públicas para a agricultura familiar e formas de interação entre sociedade e estado no Brasil. Rev. Econ. Sociol. Rural vol.52 supl.1 Brasília, 2014. Disponível em: $<\mathrm{http}: / / \mathrm{www}$. scielo.br/scielo.php?script=sci_ arttext\&pid=S0103-20032014000600007> Acesso em: 01 jun. 2016.

GUSTIN, M. B. S.; SANTOS, B. S. Impactos da Mineração na Região de Conceição do Mato Dentro. Projeto Internacional de Pesquisa, Cidade e Alteridade. Belo Horizonte, 2013.

GUSTIN, M. B. S.; Z., M. C.; PENIDO, M. O.; PENNA, V. V. Impactos sociais, econômicos, ambientais e de trabalho degradante em Conceição do Mato Dentro, Dom Joaquim e Alvorada de Minas/MG. Relatório Final. Programa Cidade e Alteridade. Belo Horizonte, 2015.

INTITUTO BRASILEIRO DE GEOGRAFIA E ESTATÍSTICA - IBGE. Censo Agropecuário 2006. Disponível em: $<$ http://www.ibge.gov.br/home/ estatistica/economia/agropecuaria/censoagro/> Acesso em: 01 fev. 2017.

.IBGE Cidades. Minas Gerais. Disponível em: < https://cidades.ibge.gov.br/> Acesso em: julho de 2016.

INSTITUTO DE PESQUISA ECONÔMICA APLICADA - IPEA. "Agricultura - Agricultura em família". Disponível em: $<$ http://www.ipea.gov.br/desafios/index.php?option $=$ com content $\&$ view $=$ article $\&$ id $=2512$ : catid $=28 \&$ Itemid $=23>$ Acesso em: 27 nov. 2016.

MILANEZ, B.; LOSEKANN, C. Desastre no Vale do Rio Doce: antecedentes, impactos e ações sobre a destruição. Organizadores: Bruno Milanez e Cristiana Losekann - Rio de Janeiro: Folio Digital: Letra e Imagem, 2016.

NÚCLEO TRAVESSIA-Núcleo de Pesquisa, Extensão e Apoio a Agricultura Familiar e Desenvolvimento Rural. Levantamento das potencialidades da agricultura familiar e agroecológica das comunidades rurais atingidas pela mineração nos municípios de Conceição do Mato Dentro, Alvorada de Minas e Dom Joaquim. Núcleo Travessia. 2016. (Relatório de pesquisa). 
PEREIRA, D. C.; BECKER, L. C.; WILDHAGEN, R. O. Comunidades atingidas por mineração e violação dos direitos humanos: cenários em Conceição do Mato Dentro. Revista Ética e Filosofia Política, nº 16, vol. 1. Jun, 2013.

REIS, C. S. A função social da propriedade rural e o acesso à terra como respeito à dignidade da pessoa humana. Revista Âmbito Jurídico. 2011 Disponível em: < http://www.ambito-juridico.com.br/site/index.php?n

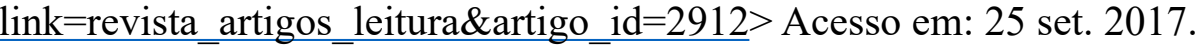

RIBEIRO, A. P.; CERATTI, S.; BROCH, D. T. Programa Nacional de Alimentação Escolar (PNAE) e a participação da agricultura familiar em municípios do Rio Grande do Sul. Revista Gestão e Desenvolvimento em Contexto - GEDECON. Vol. 1, no 01, 2013.

RODRIGUES, R.; SIQUEIRA, H. M.; BIANCARD, C. C. S.; ANDRADE, M. A. N.; VALENTE, L. M.; PAULA, L. B. P. A aquisição de alimentos da agricultura familiar pelo PNAE no município de Alegre - ES. Demetra; 2017; 12(1); 91-112.

SAMBUICHI, R. H. R.; GALINDO, E. P.; OLIVEIRA, M. A.C.; MOURA, A. M. M. Compras públicas sustentáveis e agricultura familiar: a experiência do Programa de Aquisição de Alimentos (PAA) e do Programa Nacional de Alimentação Escolar (PNAE). SAMBUICHI, Regina Helena Rosa [et al.] (orgs.) Políticas agroambientais e sustentabilidade: desafios, oportunidades e lições aprendidas. Brasília: Ipea, 2014. 273 p.

SCARPARO, A. L. S.; OLIVEIRA, V. R.; BITTENCOURT, J. M. V; RUIZ, E. N. F.; FERNANDES, P. F.; ZYS, J. Z.; MOULIN, C. C.. Formação para nutricionistas que atuam no Programa Nacional de Alimentação Escolar: uma avaliação da efetividade. Ciênc. saúde coletiva [online]. 2013, vol.18, n.4, pp.1001-1008.

SILVA, D. B. P.; BACCARIN, J. G.; ALEIXO, S. S.; FILIPAK, A. Os agentes sociais e o Programa Nacional de Alimentação Escolar (PNAE): a percepção dos agricultores familiares. Encontro Internacional Participação, Democracia e Políticas Públicas: aproximando agendas e agentes 23 a 25 de abril de 2013, UNESP, Araraquara (SP). Disponível em: < http://javali.fcav.unesp.br/Home/departamentos/economiarural/ josegiacomobaccarin1559/artigo-pdpp.pdf $>$ Acesso em: 13 set. 2017.

SOUZA-ESQUERDO, V. F.; BERGAMASCO, S. M. P. P. Análise sobre o acesso aos programas de políticas públicas da agricultura familiar nos municípios do circuito das frutas (SP). Rev. Econ. Sociol. Rural, Brasília, v. 52, supl.1, p. 205-222, 2014. Disponível em http://www.scielo.br/scielo. php?script $=$ sci arttext\&pid=S0103-20032014000600011. Acesso em 21 dez. 2017

VIEIRA, L. Ameaças e violações ao direito humano à água em Conceição do Mato Dentro e Alvorada de Minas, Minas Gerais. (Dossiê Denúncia). Minas Gerais, 2017, 50 p. Disponível em: < https://issuu.com/ coletivomargaridaalves/docs/dossi viola_ odireito_ gua $>$ Acesso em: 08 out. 2017

WHITAKER, D. C. A. Sociologia Rural Questões Metodológicas Emergentes. Presidente Venceslau, São Paulo, Editora: Letras a Margem, 2002, 256 p. 